\title{
Arc Synthesis, Crystal Structure, and Photoelectrochemistry of Copper(I) Tungstate
}

\author{
Miguel Tayar Galante, ${ }^{\bigcirc}$ Aleksandar Živković, $\bigcirc$ Jéssica Costa Alvim, Cinthia Cristina Calchi Kleiner, \\ Márcio Sangali, S. F. Rebecca Taylor, Adam J. Greer, Christopher Hardacre, Krishnan Rajeshwar, \\ Rubens Caram, Rodnei Bertazzoli, Robin T. Macaluso, Nora H. de Leeuw, * and Claudia Longo*
}

Cite This: ACS Appl. Mater. Interfaces 2021, 13, 32865-32875

Read Online

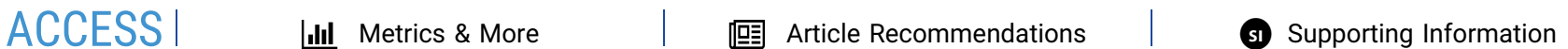

ABSTRACT: A little-studied p-type ternary oxide semiconductor, copper(I) tungstate $\left(\mathrm{Cu}_{2} \mathrm{WO}_{4}\right)$, was assessed by a combined theoretical/experimental approach. A detailed computational study was performed to solve the long-standing debate on the space group of $\mathrm{Cu}_{2} \mathrm{WO}_{4}$, which was determined to be triclinic $P 1$. $\mathrm{Cu}_{2} \mathrm{WO}_{4}$ was synthesized by a time-efficient, arc-melting method, and the crystalline reddish particulate product showed broad-band absorption in the UV-visible spectral region, thermal stability up to $\sim 260{ }^{\circ} \mathrm{C}$, and cathodic photoelectrochemical activity. Controlled thermal oxidation of copper from the $\mathrm{Cu}$ (I) to $\mathrm{Cu}$ (II) oxidation state showed that the crystal lattice could accommodate $\mathrm{Cu}^{2+}$ cations up to $\sim 260{ }^{\circ} \mathrm{C}$, beyond which the compound was
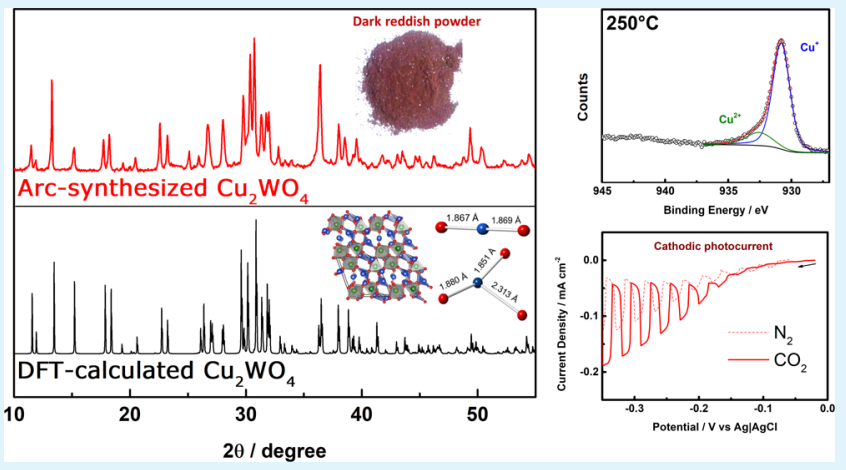
converted to $\mathrm{CuO}$ and $\mathrm{CuWO}_{4}$. This process was monitored by powder X-ray diffraction and X-ray photoelectron spectroscopy. The electronic band structure of $\mathrm{Cu}_{2} \mathrm{WO}_{4}$ was contrasted with that of the $\mathrm{Cu}(\mathrm{II})$ counterpart, $\mathrm{CuWO}_{4}$ using spin-polarized density functional theory (DFT). Finally, the compound $\mathrm{Cu}_{2} \mathrm{WO}_{4}$ was determined to have a high-lying (negative potential) conduction band edge underlining its promise for driving energetic photoredox reactions.

KEYWORDS: ternary copper oxide, copper tungstate, arc synthesis, p-type semiconductor, photoelectrochemistry, solar fuels, crystal structure, density functional theory

\section{INTRODUCTION}

This paper presents computational aspects, solid-state chemistry, and photoelectrochemical (PEC) properties of copper(I) tungstate, $\mathrm{Cu}_{2} \mathrm{WO}_{4}$, a little-studied inorganic compound of both fundamental and technological import. It belongs to the family of multinary copper oxides that have interesting electronic, magnetic, and optical properties for a range of applications, including in sensors/biosensors, ${ }^{1}$ electronic devices, ${ }^{2}$ and photoelectrochemical (PEC) solar energy conversion., ${ }^{3,4}$ Ternary copper-based inorganic p-type semiconductors have been studied extensively for their applicability in solar hydrogen generation. ${ }^{5-7}$ In these compounds, copper commonly occurs in the +1 or +2 oxidation states, in turn dictating their electronic properties, i.e., copper(II)-based oxides can be found both as n-type ${ }^{8}$ or ptype $^{9,10}$ semiconductors, while copper(I)-based compounds are p-type semiconductors, as exemplified by the parent oxide, $\mathrm{Cu}_{2} \mathrm{O}$.

Much of the literature on ternary oxides based on copper oxide and tungsten trioxide as the binary components is related to copper(II) tungstate, $\mathrm{CuWO}_{4}$. This compound is an n-type semiconductor $^{12}$ with an optical band gap of $\sim 2.2 \mathrm{eV}$. It has been considered as a photoanode for water oxidation ${ }^{12-14}$ and as a photocatalyst for hydrogen evolution in aqueous suspension. ${ }^{15}$ In contrast, little research has been reported on copper(I)-based tungstate, $\mathrm{Cu}_{2} \mathrm{WO}_{4}$, which is a p-type semiconductor.

In contrast to the copper(II) tungstate counterpart, literature reports are sparse on the copper(I) compound $\left(\mathrm{Cu}_{2} \mathrm{WO}_{4}\right)$, of focus in this study. Two studies ${ }^{16,17}$ on its crystal structure appeared in the 1980s followed by a rather long hiatus. Further, these two structural reports disagreed on the space group, $P 1$ or $P \overline{1}$. Marinder ${ }^{16}$ was the first to investigate the structure of $\mathrm{Cu}_{2} \mathrm{WO}_{4}$ and used $\mathrm{X}$-ray diffraction to propose the $P \overline{1}$ space group, but failed to rigorously refine the structural model via Rietveld refinement. On the other

Received: March 1, 2021

Accepted: June 25, 2021

Published: July 12, 2021 
hand, Mumm ${ }^{17}$ used single-crystal X-ray diffraction to assign the space group $P 1$, ruling out $P \overline{1}$ on the basis that the $d(\mathrm{~W}-$ $\mathrm{O})=1.42 \AA$ and $d(\mathrm{Cu}-\mathrm{Cu})=2.42 / 2.51 \AA$ distances were too short. Motivated by this historical ambiguity in the space group determination of the $\mathrm{Cu}_{2} \mathrm{WO}_{4}$ structure, a major objective of the present study was to computationally predict the thermodynamic and spectroscopic properties of each structure candidate, and thereby unequivocally assign the space group to which $\mathrm{Cu}_{2} \mathrm{WO}_{4}$ belonged.

Time-efficient synthesis of the little-studied $\mathrm{Cu}_{2} \mathrm{WO}_{4}$ and its PEC characterization constituted the other primary objectives of this study. Considering that computer-aided materials genome for a targeted application is still an evolving "blind art", ${ }^{18}$ iterative time-efficient synthesis approaches are needed in the interim timeframe to allow for fast and efficient screening of possible candidates. Therefore, in this paper, a single-step, arc synthesis of $\mathrm{Cu}_{2} \mathrm{WO}_{4}$, using $\mathrm{Cu}_{2} \mathrm{O}$ and $\mathrm{WO}_{3}$ as precursors, is introduced. The commonly employed solution (e.g., sol-gel synthesis) or even, ceramic (solid-state) synthesis routes require hours to days to derive the targeted product, most often in an amorphous state. Also, a postsynthesis thermal annealing step is then needed in these cases to improve the sample morphology. In contrast, in the arc synthesis, the product can be obtained in the crystalline state within minutes.

\section{EXPERIMENTAL AND THEORETICAL METHODS}

2.1. Computational Aspects. Spin-polarized density functional theory (DFT) calculations were performed using the Vienna Ab initio Simulation Package (VASP) ${ }^{19-21}$ with the projector-augmented wave (PAW) method and a plane-wave cutoff of $500 \mathrm{eV}$. For the PAW potentials, the valence electronic configurations used were $4 \mathrm{~s}^{1} 3 \mathrm{~d}^{10}$ for $\mathrm{Cu}, 2 \mathrm{~s}^{2} 2 \mathrm{p}^{4}$ for $\mathrm{O}$, and $6 \mathrm{~s}^{1} 5 \mathrm{~d}^{5} 5 \mathrm{p}^{6} 5 \mathrm{~s}^{2}$ for $\mathrm{W}$.

In the DFT calculations, the general gradient approximation (GGA) for the exchange-correlation (XC) functional was employed within the Perdew-Burke-Ernzerhof (PBE) parametrization. ${ }^{22}$ For the hybrid DFT calculations, the Heyd-Scuseria-Ernzerhof (HSE) $)^{23-25}$ XC functional was used, with an inverse screening length of $\mu=0.2 \AA^{-1}$ and $15 \%(\alpha=0.15)$ of the nonlocal exact HartreeFock (HF) exchange. The method of Gajdoš was used to obtain the real and imaginary parts of the dielectric function, ${ }^{26}$ from which the absorption coefficient was derived. Long-distance dispersion corrections were included using the D3 approach of Grimme. ${ }^{27}$ The conjugate gradient method was used for structural optimization, with the total energy and force convergence criteria set to $10^{-5} \mathrm{eV}$ and 0.01 $\mathrm{eV} \AA^{-1}$, respectively. The Brillouin zone was sampled by $2 \times 2 \times 4$ and $5 \times 5 \times 5 \Gamma$-centered Monkhorst-Pack meshes. ${ }^{28}$ The extent of charge distribution was studied using the Bader scheme as implemented in the Henkelman code. ${ }^{29-31}$ Graphical drawings were produced using VESTA, ${ }^{32}$ the electron and hole effective masses were calculated using Sumo. ${ }^{33}$ The transition dipole moment (TDM) was obtained using the VASPKIT program. ${ }^{34}$

Vibrational frequency calculations were performed using the allelectron code CRYSTAL (2017 release) ${ }^{35,36}$ with the hybrid B3LYP exchange-correlation functional, ${ }^{37,38}$ in conjunction with triple- $\zeta$ valence + polarization Gaussian-type basis sets employed to treat the $\mathrm{Cu}$ and $\mathrm{O}$ atoms, while a scalar relativistic pseudopotential was adopted to treat the core electrons of $\mathrm{W}$. The optimal basis sets of $\mathrm{Cu}$ and $\mathrm{O}$ were taken without further modification from Linnera, ${ }^{39,40}$ while for $\mathrm{W}$, the effective core pseudopotential derived by Hay and Wadt was chosen. ${ }^{41,42}$ This protocol has been shown to reproduce the structure as well as the vibrational properties of ionic and semi-ionic compounds in good agreement with experimental data. ${ }^{43,44}$

In CRYSTAL, the convergence of the real-space summation of the Coulomb and exchange contributions to the Hamiltonian matrix is controlled by five overlap criteria. The values used in this study were $10^{-6}, 10^{-6}, 10^{-6}, 10^{-6}$, and $10^{-12}$. The threshold on the self-consistent
(SCF) energy was set to $10^{-7} \mathrm{Ha}$. For the compounds of interest, the convergence with respect to $k$-points was checked. Monkhorst-Pack meshes of $3 \times 3 \times 7$ for $\mathrm{Cu}_{2} \mathrm{WO}_{4}$ and $7 \times 7 \times 7$ for $\mathrm{CuWO}_{4}$ were used to sample the first Brillouin zone. ${ }^{35}$ Relative infrared and Raman intensities were computed analytically, based on coupled-perturbed Hartree-Fock/Kohn-Sham (CPHF/KS) treatments implemented in the code. ${ }^{45-48}$ To confirm the space group of the crystal, the FINDSYM suite was used on top of the structure obtained with fully relaxed DFT geometries. ${ }^{49}$

2.2. Arc Synthesis of $\mathrm{Cu}_{2} \mathrm{WO}_{4} \cdot \mathrm{Cu}_{2} \mathrm{O}(425 \mathrm{mg})$ and $\mathrm{WO}_{3}(600$ $\mathrm{mg})(2.3 \mathrm{Cu}: 1 \mathrm{~W}$ atom molar ratio) were mixed and ground in an agate mortar until a homogeneous, finely dispersed powder was obtained. The mixture was made into a pellet using a hydraulic press and then placed inside a water-cooled copper crucible housed in an arc-melting furnace. The furnace was sealed, evacuated, and then flushed with argon to create an inert, deoxygenated atmosphere. The pellet was then melted by applying an electric arc for $30 \mathrm{~s}$. The power source was set to provide an arc current of $90 \mathrm{~A}$. After cooling, the molten material was ground in an agate mortar. Less than $\sim 2 \%$ mass loss was observed.

Powder X-ray diffraction (XRD) data were collected at room temperature on a PANalytical Empyrean diffractometer equipped with $\mathrm{Cu} \mathrm{K} \alpha$ radiation, a Bragg-Brentano $\mathrm{HD}$ optical module, and an $\mathrm{X}^{\prime}$ Celerator detector. Data were collected at $10 \leq 2 \theta \leq 70^{\circ}$ with a step size of $2 \theta=0.008^{\circ}$ and a step rate of $0.2 \mathrm{~s}$ per step. Ultravioletvisible diffuse reflectance measurements were performed on a Shimadzu (UV-2460) spectrometer, equipped with a diffuse reflection accessory for solids analysis. Differential scanning calorimetry (DSC) analysis was performed in DSC 2910 device (TA Instruments). Thermogravimetric analysis (TGA) was performed on a TA Instruments Model 2950 instrument. Both sets of thermal analyses were performed in air, at a heating ratio of $10{ }^{\circ} \mathrm{C} \mathrm{min}^{-1}$.

X-ray photoelectron spectroscopy (XPS) was performed on a Kratos Axis Ultra DLD instrument using an $\mathrm{Al}-\mathrm{K} \alpha$ monochromatic source and hemispherical electron energy analyzer. Peak profile fitting was done using XPSPeak 4.1 software considering a Shirley-type baseline. Binding energy values were corrected using the peak from adventitious carbon $(\mathrm{C} 1 \mathrm{~s}$ binding energy $=284.8 \mathrm{eV}$ ) as reference.

2.3. Photoelectrochemical Measurements. Thin-film electrodes were prepared by suspending the arc-synthesized $\mathrm{Cu}_{2} \mathrm{WO}_{4}$ powder sample in isopropanol, followed by sonication for $30 \mathrm{~min}$. The suspension was cast dropwise over the conductive surface of previously washed fluorine-doped tin oxide (FTO)-glass slides and dried at room temperature in flowing air before thermal annealing.

Electrochemical measurements were performed in a singlecompartment 3-electrode cell using $0.5 \mathrm{~mol} \mathrm{~L}^{-1} \mathrm{NaHCO}_{3}$ aqueous solution as supporting electrolyte. Platinum wire was used as the counterelectrode and AglAgCl|KCl $3 \mathrm{M}$ as the reference electrode. An Autolab PGSTAT $128 \mathrm{~N}$ potentiostat was used for the electrochemical and photoelectrochemical (PEC) measurements. An Asahi Spectra HAL-100 solar simulator calibrated at 1 Sun, AM 1.5G was used as the light source.

\section{RESULTS AND DISCUSSION}

3.1. $P 1$ or $P \overline{1}$ ? The two calculated crystal structures are depicted in Figure 1 for $\mathrm{Cu}_{2} \mathrm{WO}_{4}$ corresponding to the two space groups in question. Starting from the respective experimental atomic positions and lattice parameters, a full geometrical relaxation was undertaken, with the final structures in the $P \overline{1}$ and $P 1$ candidates exhibiting essentially similar features. The $\mathrm{W}$ atom was always coordinated by six $\mathrm{O}$ atoms in an octahedral environment regardless of the space group assignment; however, there were differences in the $\mathrm{Cu}$ coordination.

$\mathrm{Cu}$ atoms could be found linearly coordinated by two $\mathrm{O}$ atoms, with distances of $1.82-1.88$ and $1.84-1.98 \AA$ for $P \overline{1}$ and $P 1$, respectively. However, the $\mathrm{Cu} 2$ atom in the $P \overline{1}$ model was coordinated to four $\mathrm{O}$ atoms in a distorted tetrahedron, 


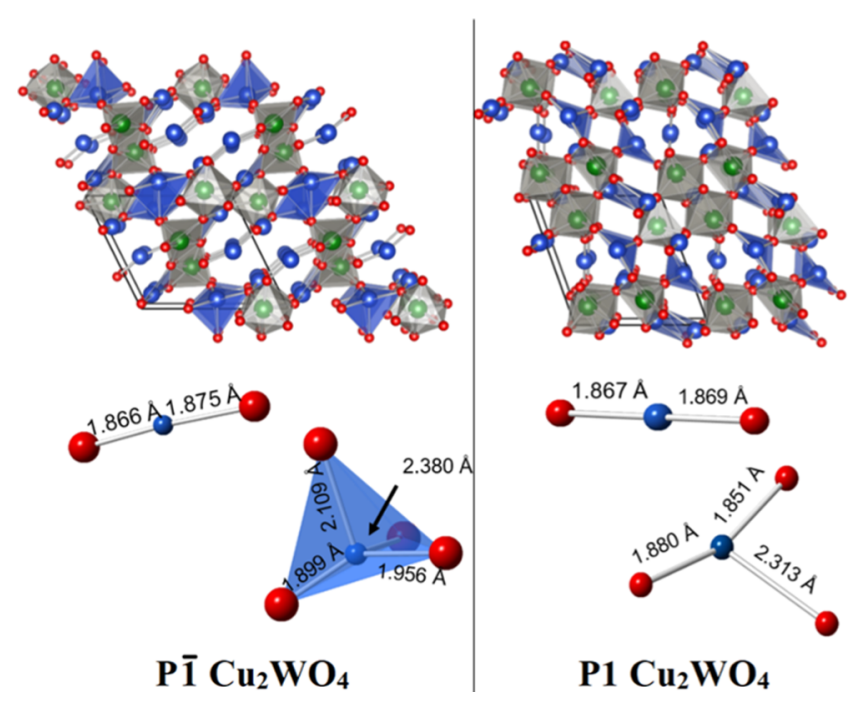

Figure 1. Crystal structures of fully relaxed copper(I) tungstate geometries: a detailed view of $P \overline{1} \mathrm{Cu}_{2} \mathrm{WO}_{4}$ (left) and $P 1 \mathrm{Cu}_{2} \mathrm{WO}_{4}$ (right). The $\mathrm{Cu}$ atoms are in distorted tetrahedral and linear geometries for $P \overline{1}$ and distorted $\mathrm{T}$-shaped and linear geometries for $P 1 . \mathrm{Cu}, \mathrm{W}$, and $\mathrm{O}$ atoms are shown as blue, green, and red spheres, respectively.

with $\mathrm{Cu}-\mathrm{O}$ distances ranging between 1.89 and $1.95 \AA$. Two additional $\mathrm{O}$ atoms lie 2.11 and $2.38 \AA$ away. In the $P 1$ model, half of the $\mathrm{Cu}$ atoms were coordinated to three oxygen atoms in a trigonal geometry. The 3 -fold coordination (distorted Tshaped geometry) is expected for $\mathrm{Cu}^{+}$species rather than the unusual distorted tetrahedron in the $P \overline{1}$ structure, which is expected for $\mathrm{Cu}^{2+}$ species. The $\mathrm{Cu}-\mathrm{O}$ distances in the $\mathrm{P1}$ model were $1.86-1.89 \AA$ with an additional O atom separation of $2.32 \AA$.

Furthermore, the bond lengths from the experimentally available data of the $P \overline{1}$ structure, namely, $d(\mathrm{~W}-\mathrm{O})=1.42 \AA$ and $d(\mathrm{Cu}-\mathrm{Cu})=2.42 / 2.51 \AA^{16}$ were not found in the computed ground state structure. Our optimized bond lengths: $d(\mathrm{~W}-\mathrm{O})=1.74 \AA$ and $d(\mathrm{Cu}-\mathrm{Cu})=2.71 / 3.06 \AA$ for $\mathrm{Cu}_{2} \mathrm{WO}_{4}$ $(P \overline{1})$, were comparable to the values of $d(\mathrm{~W}-\mathrm{O})=1.78 \AA$ and $d(\mathrm{Cu}-\mathrm{Cu})=2.62 / 2.78 \AA$ in $\mathrm{Cu}_{2} \mathrm{WO}_{4}(P 1)$. Based on the structural data outlined above, we suggest that $\mathrm{Cu}_{2} \mathrm{WO}_{4}$ is most likely to crystallize in $P 1$ as proposed by Mumm, ${ }^{17}$ while the $(P \overline{1})$ structure of Marinder ${ }^{16}$ undergoes strong relaxation into an arrangement very close to the $P 1$ structure.

The computed cell parameters for copper(I) tungstate in $P \overline{1}$ and $P 1$ are listed in Tables 1 and 2 , respectively. Three different functionals-PBE, HSE, and B3LYP, yielded unit cell parameters equivalent to one another for both $P \overline{1}$ and $P 1$. However, the $\mathrm{XC}$ functionals yielded cell parameters that deviated by $8-9 \%$ for $P \overline{1}$, substantially higher than the $1-2 \%$ deviation for $P 1$.

Figure 2 maps the computed variation of the total energy with respect to the unit cell volume, which also indicated that the $P 1$ space group was thermodynamically favored over the $P \overline{1}$ space group. This energy computation corroborates the fact that arc-melted samples (see below) typically yield thermodynamically stable phases.

To further clarify the differences between the two possible space groups, vibrational calculations were performed on both the unrelaxed CIF structures available from the American Mineralogist Database, as well as the fully DFT optimized structures. The calculated spectra of $\mathrm{Cu}_{2} \mathrm{WO}_{4}$ in the two considered space groups are shown in Figure $\mathrm{S} 1$. The spectra obtained from the CIF structure without further relaxation contain several negative frequencies ( 21 in the case of $P \overline{1}$ and 3 in the case of $P 1)$, indicating that the structures belonged to transition states or were unstable. Upon full geometry optimization, two frequencies in the $P \overline{1}$ structure remained negative, while all frequencies in the $P 1$ structure turned positive. This further illustrates that the $P \overline{1}$ structure was probably not fully refined and did not correspond to the most likely structure of $\mathrm{Cu}_{2} \mathrm{WO}_{4}$. However, it is also worth noting that a calculation of all positive frequencies does not ensure that the structure is at the "global" minimum, but only at a "minimum", which could still be a local one. ${ }^{50,51}$ The fully relaxed geometries of both discussed structures are available in the Supporting Information.

Raman spectra for both the $P 1$ and $P \overline{1}$ structures were also calculated and compared with the experimental Raman spectrum of $\mathrm{Cu}_{2} \mathrm{WO}_{4}$ (obtained from an arc-melted $\mathrm{Cu}_{2} \mathrm{WO}_{4}$ sample, to be discussed in the following section) (Figure 3). The experimental Raman spectrum (albeit, significantly broadened) clearly shows better conformity with the calculated spectrum for the $P 1$ structure.

3.2. Arc Synthesis, Structure, and Optical Behavior of $\mathrm{Cu}_{2} \mathrm{WO}_{4}$. A representative XRD pattern for the powder sample is shown in Figure 4a. All peaks matched with the calculated $P 1$ structure. Importantly, no peaks associated with $\mathrm{Cu}_{2} \mathrm{O}$ and $\mathrm{WO}_{3}$ precursors were observed, indicating total consumption of the starting materials. To ensure that the obtained structure was not a kinetically trapped metastable phase rather than the thermodynamically stable one determined by DFT, XRD analyses were performed before and after annealing at $250{ }^{\circ} \mathrm{C}$. Figure S2 shows these results in lower angles, where $P 1$ and $P$ structures most differ from each other. No changes are observed, confirming that the obtained material was indeed a thermodynamically stable P1 structure. It should also be noted that a small excess of $\mathrm{Cu}_{2} \mathrm{O}$ was used in the precursor mixture (see Section 2). Arc-melting a stoichiometric $2 \mathrm{Cu} 1 \mathrm{~W}$ atom ratio resulted in a complex mixture (Figure S3). This may be due to the volatility of metal oxides.

Strong light absorption was observed over the entire UV-vis region, as seen in the diffuse reflectance spectrum in Figure $4 \mathrm{~b}$. A Tauc plot $^{52}$ assuming a direct optical transition is presented, where a main optical transition was observed with an absorption onset at approximately $1.97 \mathrm{eV}$, together with an absorption "tail"

Table 1. Experimental and Theoretical Unit Cells of $\mathrm{Cu}_{2} \mathrm{WO}_{4}$ in $P \overline{1}$

\begin{tabular}{|c|c|c|c|c|c|c|c|}
\hline & $a(\AA)$ & $b(\AA)$ & $c(\AA)$ & $\alpha$ & $\beta$ & $r$ & $V\left(\AA^{3}\right)$ \\
\hline Marinder $^{16}$ & 5.8578 & 7.9140 & 8.2050 & 110.360 & 96.450 & 93.970 & 351.948 \\
\hline PBE & 5.7868 & 7.7199 & 8.8347 & 64.830 & 88.554 & 88.470 & 357.043 \\
\hline HSE & 5.7130 & 7.6947 & 8.8396 & 65.220 & 89.363 & 88.840 & 352.741 \\
\hline B3LYP & 5.7322 & 7.3662 & 8.8970 & 66.6446 & 89.9870 & 88.6059 & 344.780 \\
\hline
\end{tabular}


Table 2. Experimental and Theoretical Unit Cells of $\mathrm{Cu}_{2} \mathrm{WO}_{4}$ in $\mathrm{Pl}$

\begin{tabular}{|c|c|c|c|c|c|c|c|}
\hline & $a(\AA)$ & $b(\AA)$ & $c(\AA)$ & $\alpha$ & $\beta$ & $r$ & $V\left(\AA^{3}\right)$ \\
\hline Mumm $^{17}$ & 7.9018 & 8.2008 & 5.8718 & 96.506 & 94.033 & 110.270 & 352.176 \\
\hline PBE & 7.8804 & 8.2054 & 5.9174 & 95.941 & 93.421 & 109.503 & 356.928 \\
\hline HSE & 7.9182 & 8.1943 & 5.8830 & 96.071 & 93.436 & 109.618 & 355.678 \\
\hline B3LYP & 7.8398 & 8.2148 & 5.7540 & 97.725 & 95.585 & 109.929 & 341.125 \\
\hline
\end{tabular}

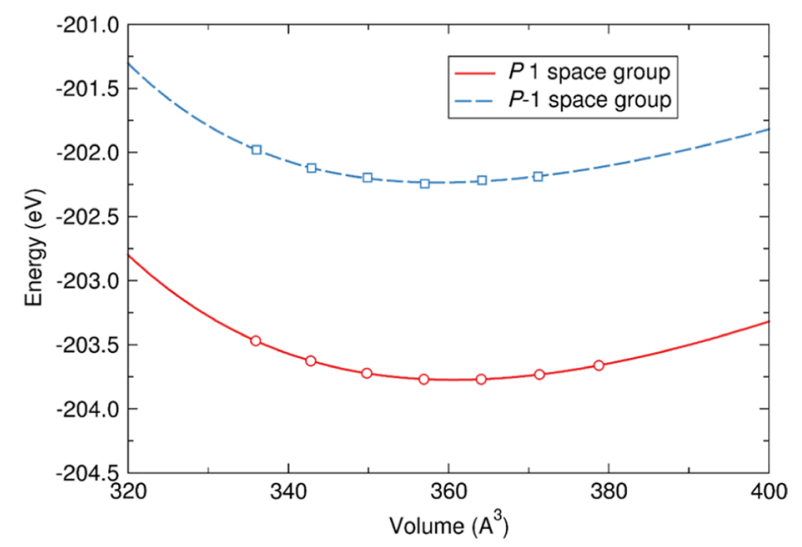

Figure 2. Calculated energy versus unit cell volume for copper(I) tungstate crystallizing in two distinct space groups. The values were fitted with a Birch-Murnaghan equation of state.

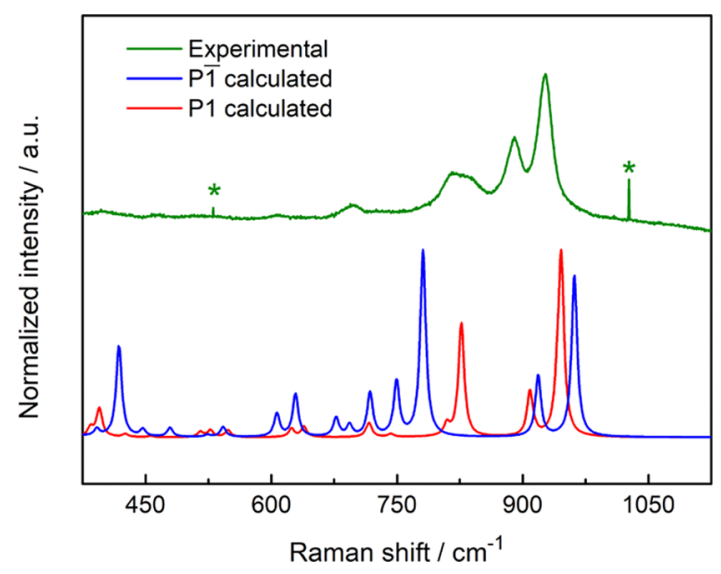

Figure 3. Calculated Raman spectra of $\mathrm{Cu}_{2} \mathrm{WO}_{4}$ for $P 1$ and $P \overline{1}$ space groups, and experimental data obtained from an arc-melted $\mathrm{Cu}_{2} \mathrm{WO}_{4}$ sample. Asterisks on the experimental spectrum indicate equipment artifacts. inset showing the raw reflectance data). The optical behavior may be compared against the electronic band structure of the compound which is presented next.

3.3. Electronic Band Structure of $\mathrm{Cu}_{2} \mathrm{WO}_{4}$ and Comparison with $\mathrm{CuWO}_{4}$. The DFT Kohn-Sham electronic band structure of $\mathrm{Cu}_{2} \mathrm{WO}_{4}$, together with the accompanying densities of states, are shown in Figure 5a. For comparison, the same quantities were calculated for $\mathrm{CuWO}_{4}$ using an equivalent methodology (Figure 5b). The nonmagnetic ground state of $\mathrm{Cu}_{2} \mathrm{WO}_{4}$ featured a direct band gap between the valence band maximum (VBM) and the conduction band minimum (CBM) of $1.98 \mathrm{eV}$ located at the high-symmetry X-point (Table 3 ). The top of the valence band consisted of mostly $\mathrm{Cu}-3 \mathrm{~d}$ states weakly mixed with $\mathrm{O}-2 \mathrm{p}$ states, while the conduction band was composed predominantly of W-5d states strongly hybridizing with empty O-2p states. Such behavior stood in complete contrast to $\mathrm{CuWO}_{4}$, where O-2p states dictate the VBM and mixed strongly with $\mathrm{Cu}-3 \mathrm{~d}$ states. The conduction band in this case, which can be viewed as an intermediate band, was predominantly made of empty $\mathrm{Cu}-3 \mathrm{~d} \mathrm{e}_{\mathrm{g}}$ states and further separated by around $1 \mathrm{eV}$ from the subsequent conduction band states. These results indicate the fundamentally distinct nature of the two different oxide compounds.

Upon electron excitation (for instance, via incoming electromagnetic radiation), the foremost transition in $\mathrm{Cu}_{2} \mathrm{WO}_{4}$ is a d-d transfer between the $\mathrm{Cu}$ and $\mathrm{W}$ states, while in $\mathrm{CuWO}_{4}$, electrons hop between the p levels of $\mathrm{O}$ and the $\mathrm{d}$ levels of $\mathrm{Cu}$ (visual representation through partial charges shown in Figure S4). As such, $\mathrm{CuWO}_{4}$ can be identified as a charge-transfer (p-d)-type insulator. ${ }^{52}$ Furthermore, contrary to earlier suppositions, ${ }^{53}$ all of the aforementioned transitions were found to be dipole-allowed in both compounds. Bader charges calculated for each structure are shown in Table S1.

The orientation-dependent hole and electron effective masses were estimated from the calculated HSE band
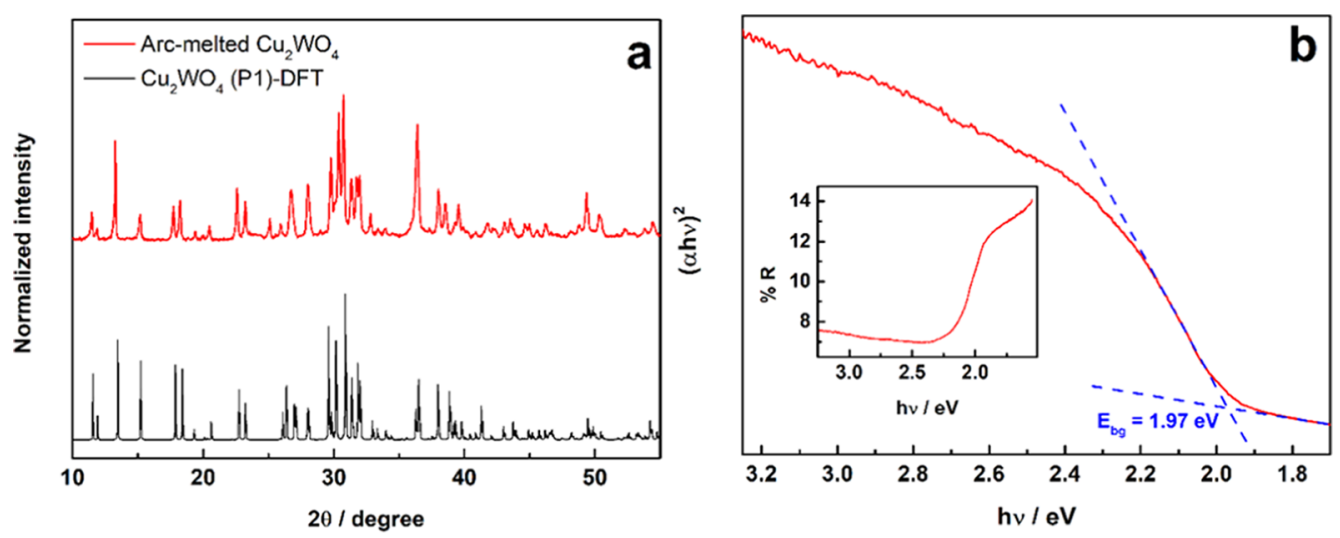

Figure 4. Powder X-ray diffractogram of arc-synthesized $\mathrm{Cu}_{2} \mathrm{WO}_{4}$, with a calculated pattern of $P 1 \mathrm{Cu}_{2} \mathrm{WO}_{4}$ (a) and a Tauc plot from a diffuse reflectance spectrum assuming direct transition (b) for arc-melted $\mathrm{Cu}_{2} \mathrm{WO}_{4}$. The inset in (b) shows the raw reflectance data. 

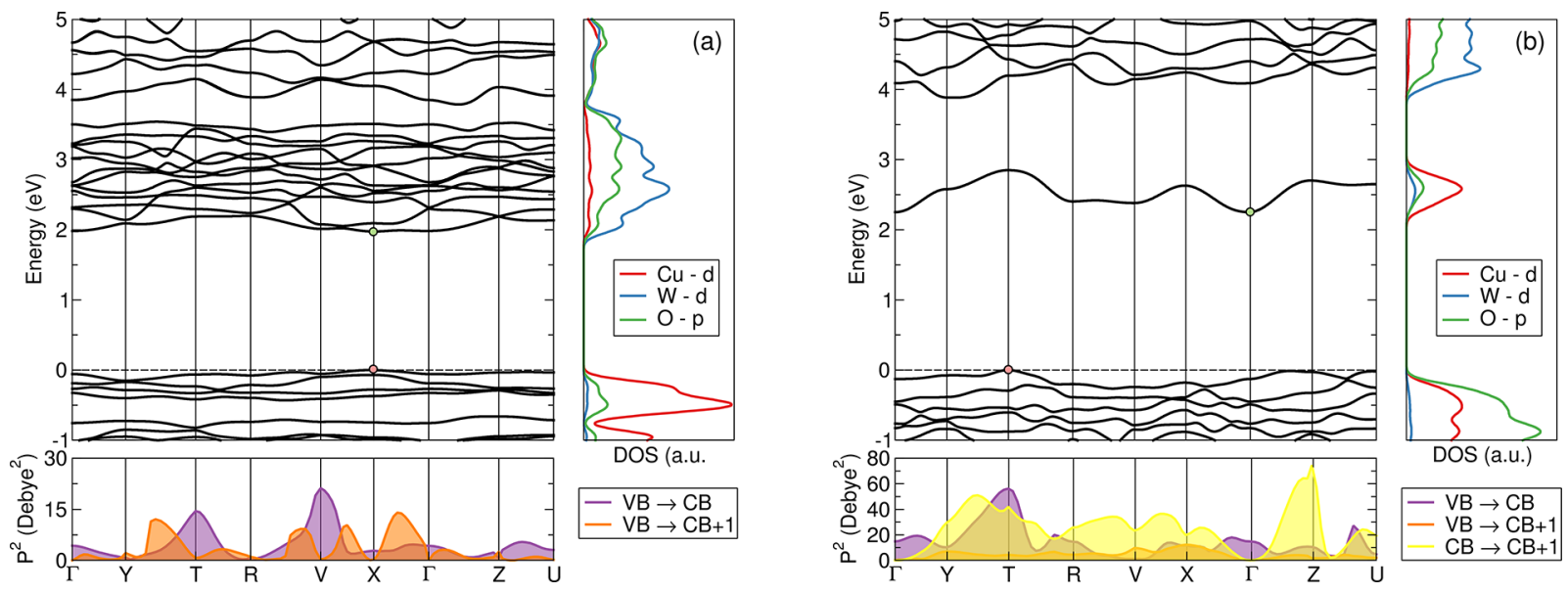

Figure 5. Electronic band structures, density of states, and transition dipole moments for $\mathrm{Cu}_{2} \mathrm{WO}_{4}(\mathrm{a})$ and $\mathrm{CuWO}_{4}(\mathrm{~b})$.

Table 3. Computed Kohn-Sham DFT Electronic Band Gap Values

\begin{tabular}{lcclcc} 
& \multicolumn{2}{c}{$\mathrm{Cu}_{2} \mathrm{WO}_{4}$} & & \multicolumn{2}{c}{$\mathrm{CuWO}_{4}$} \\
\cline { 2 - 3 } \cline { 5 - 6 } & indirect gap & direct gap & & indirect gap & direct gap \\
$\mathrm{PBE}$ & $1.19 \mathrm{eV}(\mathrm{X}-\mathrm{V})$ & $1.24 \mathrm{eV}(\mathrm{X})$ & & $0.26 \mathrm{eV}(\mathrm{T}-\mathrm{X})$ & $0.56 \mathrm{eV}(\Gamma)$ \\
$\mathrm{HSE}$ & & $1.98 \mathrm{eV}(\mathrm{X})$ & & $2.25 \mathrm{eV}(\mathrm{T}-\mathrm{X})$ & $2.40 \mathrm{eV}(\Gamma)$ \\
exp. & $\sim 1.97 \mathrm{eV}$ (this work) & & $\sim 2.2 \mathrm{eV}($ ref 12$)$ & \\
\hline
\end{tabular}

structure, using a parabolic fit to the band edges, and these are listed in Table 4 . The obtained effective mass values were

Table 4. Calculated Hole and Electron Effective Masses for the Two Copper Tungstate Compounds under Scrutiny, from the HSE Band Structure

\begin{tabular}{lllll} 
& \multicolumn{4}{c}{ effective mass $\left(m_{0}\right)$} \\
\cline { 2 - 5 } & \multicolumn{2}{c}{ valence band } & \multicolumn{2}{c}{ conduction band } \\
$\mathrm{Cu}_{2} \mathrm{WO}_{4}$ & $\mathrm{X} \rightarrow \mathrm{V}$ & -5.524 & $\mathrm{X} \rightarrow \mathrm{V}$ & 2.942 \\
& $\mathrm{X} \rightarrow \Gamma$ & -5.884 & $\mathrm{X} \rightarrow \Gamma$ & 2.942 \\
$\mathrm{CuWO}_{4}$ & $\mathrm{~T} \rightarrow \mathrm{Y}$ & -1.830 & $\Gamma \rightarrow \mathrm{X}$ & 2.734 \\
& $\mathrm{~T} \rightarrow \mathrm{R}$ & -1.049 & $\Gamma \rightarrow \mathrm{Y}$ & 1.440 \\
& & & $\Gamma \rightarrow \mathrm{Z}$ & 1.247 \\
\hline
\end{tabular}

relatively high, reflecting the flatness of the bands as well as the significant contributions of the $\mathrm{d}$ states of $\mathrm{Cu}$ and $\mathrm{W}$ to the top and bottom of the valence and conduction bands, respectively. Both effective masses further showed strong isotropy, indicating that there was no preferred direction within the crystal for the conduction of either electrons or holes.

3.4. Thermal Stability of $\mathrm{Cu}_{2} \mathrm{WO}_{4}$ and Decomposition to $\mathrm{CuWO}_{4}$. Heating the obtained material up to $\sim 260{ }^{\circ} \mathrm{C}$ did not change the XRD profile in Figure $4 \mathrm{a}$, indicating that the crystal structure was stable up to $\sim 260{ }^{\circ} \mathrm{C}$. The thermal stability was further evaluated by differential scanning calorimetry/thermogravimetric analyses (DSC/TGA, Figure S5) with samples heated in an oxidative atmosphere. A set of observed exothermic events were associated with significant mass gain, which was attributed to oxygen incorporation into the compound structure.

To investigate this further, the $\mathrm{Cu}_{2} \mathrm{WO}_{4}$ films were preannealed at different temperatures in the range, 200-350 ${ }^{\circ} \mathrm{C}$ and analyzed by XRD and XPS. XRD analyses at different annealing temperatures (Figure 6) showed structural stability up to $260^{\circ} \mathrm{C}$. Further heating promoted thermal conversion to

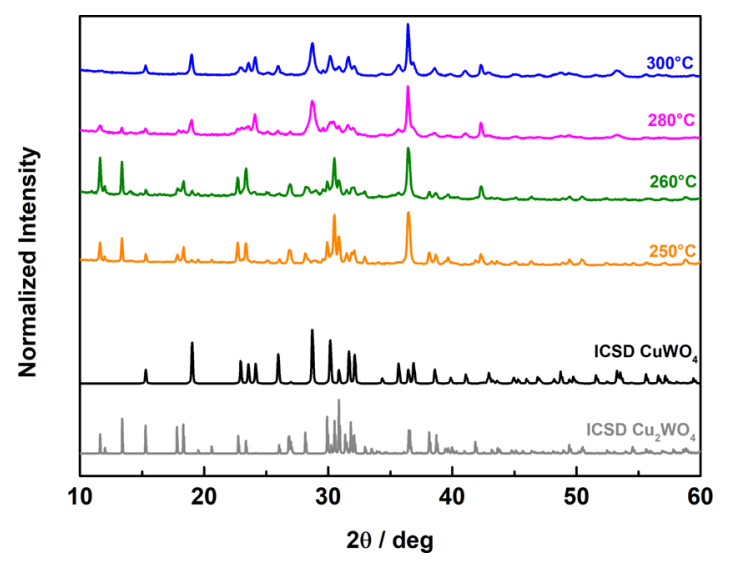

Figure 6. XRD patterns of $\mathrm{Cu}_{2} \mathrm{WO}_{4}$ films on glass, preannealed at different temperatures in air for $30 \mathrm{~min}$.

$\mathrm{CuWO}_{4}$, which belongs to the same crystal structure as $\mathrm{Cu}_{2} \mathrm{WO}_{4}$ (triclinic). ICSD references of both phases are shown together with the diffractograms of the annealed samples in Figure 6. A closer inspection of XRD data indicated that after thermal oxidation, a peak at $35.68{ }^{\circ} \mathrm{C}$ was seen (Figure S6), which is characteristic of the $\mathrm{Cu}$ (II) binary oxide, $\mathrm{CuO}$. In this case, based also on mass gain as observed in TGA data (Figure $\mathrm{S} 5$ ), we conclude that thermal oxidation of $\mathrm{Cu}_{2} \mathrm{WO}_{4}$ occurred via oxidation of $\mathrm{Cu}^{+}$to $\mathrm{Cu}^{2+}$, followed by expulsion of $\mathrm{CuO}$ (eq 1). Similar oxidation routes were also reported for $\mathrm{Cu}^{+}$ niobates, ${ }^{54}$ tantalates, $^{55}$ and vanadates. ${ }^{56}$

$$
\mathrm{Cu}_{2} \mathrm{WO}_{4}+1 / 2 \mathrm{O}_{2} \rightarrow \mathrm{CuWO}_{4}+\mathrm{CuO}
$$

Figure S7 maps the changes in the optical absorption profiles (as established by diffuse reflectance spectroscopy, DRS) of the arc-synthesized $\mathrm{Cu}_{2} \mathrm{WO}_{4}$ samples as a function of the thermal annealing temperature. No optical changes were observed up to $260{ }^{\circ} \mathrm{C}$, and the absorption cutoff gradually broadened thereafter with significant absorption below the band gap of the original compound, followed by darkening of the film. The DRS data of the fully oxidized sample at $300{ }^{\circ} \mathrm{C}$ do not match those of pure $\mathrm{CuWO}_{4}$, which is expected to show an optical band gap of $\sim 2.2 \mathrm{eV}$. This finding further supports thermal oxidation of $\mathrm{Cu}_{2} \mathrm{WO}_{4}$ occurring via oxidation to $\mathrm{CuWO}_{4}$ and expulsion of $\mathrm{CuO}$ from the compound framework (eq 1), the latter being known to absorb light at wavelengths longer than $800 \mathrm{~nm} .^{57}$ 
Scanning electron microscopy (SEM) images were obtained for the electrodes annealed at 250 and $300{ }^{\circ} \mathrm{C}$ (Figures S8 and S9, respectively). For the electrode annealed at $250{ }^{\circ} \mathrm{C}$, SEM image showed a porous film with effective substrate coverage, mainly constituted of particles with ill-defined morphology and particle size in the range of submicrometer to few microns (Figure S8a). Different points of the film were analyzed by energy-dispersive X-ray (EDS) spectroscopy (Figure S8b) to obtain elemental composition of the electrode surface. As shown in Table $\mathrm{S} 2$, the $\mathrm{Cu} / \mathrm{W}$ mass ratio was 0.43 , which strongly agreed with the expected ratio of 0.41 , and within the uncertainty limits inherent in the EDS data. Cross-sectional images of the photoelectrode are shown in Figure S8c,d, which indicated a porous film of $\mathrm{Cu}_{2} \mathrm{WO}_{4}$ with homogeneous thickness in the range of $7-8 \mu \mathrm{m}$.

Figure S8 shows the $\mathrm{Cu}_{2} \mathrm{WO}_{4}$ photoelectrode surface after annealing at $300{ }^{\circ} \mathrm{C}$. The oxidation process clearly induced a change in morphology, with increased particle size and formation of aggregates. The separate frames on the righthand side of Figure S9 are zoomed-in sections of the oxidized film, where small, spherical domains decorate larger particles of oxides. This feature is similar to that observed in other oxidized $\mathrm{Cu}(\mathrm{I})$ multimetallic oxides, such as $\mathrm{Cu} / \mathrm{Nb}$ and $\mathrm{Cu} / \mathrm{Nb} / \mathrm{Ta}$ oxides. $^{54,55}$

X-ray photoelectron spectroscopy (XPS) data are presented in Figure 7. Typically, copper exhibits a doublet associated with $\mathrm{Cu} 2 \mathrm{p}$ electrons at $\sim 933.0 \mathrm{eV}\left(\mathrm{Cu} \mathrm{3} \mathrm{p}_{3 / 2}\right)$. Copper(II) species presented additional strong satellite peaks, which can be used to distinguish them from the monovalent copper species (which show only weak satellite peaks). The two oxidation states also differ in binding energy and full width at half-maximum (i.e., broader peak for the $\mathrm{Cu}^{2+}$ signal). ${ }^{58}$

For the sample annealed at $250{ }^{\circ} \mathrm{C}$ (Figure 7 ), $\mathrm{Cu}$ sites were seen mainly in the +1 oxidation state, as expected for $\mathrm{Cu}_{2} \mathrm{WO}_{4}$. Trace amounts of $\mathrm{Cu}^{2+}$ could be attributed to charge compensation, owing to oxygen vacancies in the crystal structure. As the sample was preannealed at different temperatures, the contribution of the +2 oxidation state gradually increased. Concomitantly, the intensity of satellite peaks in the range of $940-945 \mathrm{eV}$, attributed to $\mathrm{Cu}$ (II), significantly increased as well. A major change in the $\mathrm{Cu}^{+} / \mathrm{Cu}^{2+}$ ratio was observed after annealing at $270{ }^{\circ} \mathrm{C}$.

Different binding energies were also observed for the oxygen atoms in the $\mathrm{O} 1 \mathrm{~s}$ binding energy regime (Figure S10). Such a profile is also expected for a mixed-valent copper oxide, as previously reported in the literature for the controlled reduction of $\mathrm{CuO}$ to $\mathrm{Cu}_{2} \mathrm{O} .^{58}$ Interestingly, all of the charge compensation stemming from oxygen deficiency in the tungstate compound was provided by copper in different oxidation states, while tungsten atoms remained solely in the +6 oxidation state, as shown in Figure $\mathrm{S}_{11}$.

The observation of $\mathrm{Cu}(\mathrm{I})$ in $\mathrm{Cu}_{2} \mathrm{WO}_{4}$ in the XPS data is supported by the crystal structure, where the low coordination numbers (2 and 3 ) around $\mathrm{Cu}$ sites ${ }^{17}$ are reminiscent of the coordination environments observed in $\mathrm{CuAl}_{2} \mathrm{O}_{2}{ }^{59}$ and $\mathrm{SrCu}_{2} \mathrm{O}_{2} \cdot{ }^{60}$ These XRD and XPS results also demonstrate that controlled $\mathrm{Cu}^{+} / \mathrm{Cu}^{2+}$ mixed-valence behavior in copper tungstate can be obtained by simple thermal annealing in air.

The combined results obtained from XRD and XPS show that pure, crystalline $\mathrm{Cu}_{2} \mathrm{WO}_{4}$ can be obtained by arc synthesis and that it can be thermally oxidized to systematically change the $\mathrm{Cu}^{+} / \mathrm{Cu}^{2+}$ ratio. The crystal structure of $\mathrm{Cu}_{2} \mathrm{WO}_{4}$ can accommodate $\mathrm{Cu}^{2+}$ and $\mathrm{O}$ vacancies to a certain extent in the

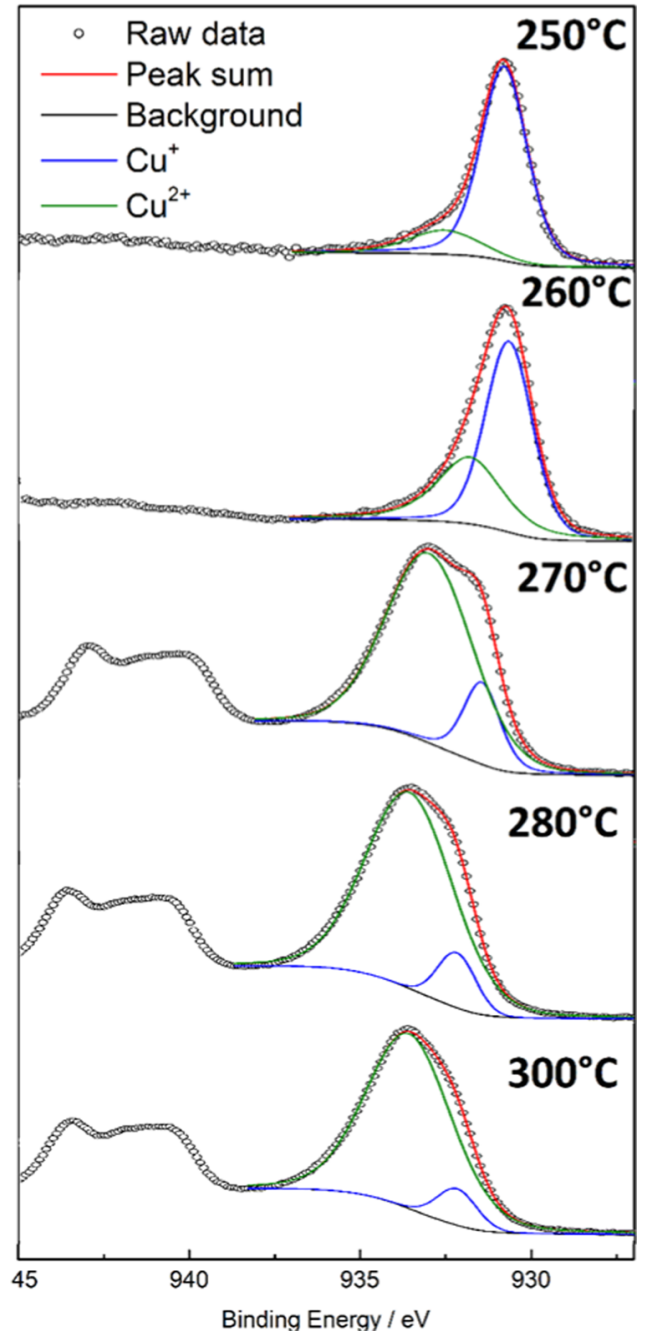

Figure 7. High-resolution XPS $\mathrm{Cu} 2 \mathrm{p}$ analyses of the $\mathrm{Cu}_{2} \mathrm{WO}_{4}$ films after annealing at different temperatures: 250, 260, 270, 280, and 300 ${ }^{\circ} \mathrm{C}$.

mixed-valence case. However, ultimately, a switch in the array of atoms in space takes place, culminating in an XRD pattern with characteristic diffraction peaks of $\mathrm{CuWO}_{4}$ above $260{ }^{\circ} \mathrm{C}$.

3.5. Photoelectrochemical Behavior of $\mathrm{Cu}_{2} \mathrm{WO}_{4}$ and Effects of Thermal Preannealing. Figure 8 shows the photoelectrochemical (PEC) properties of electrodes constituted from arc-synthesized copper tungstate particles, immobilized on an FTO-glass substrate. Aqueous $\mathrm{NaHCO}_{3}$ solution was used as the supporting electrolyte and saturated with dissolved $\mathrm{CO}_{2}$. The linear sweep voltammograms (at 3 $\mathrm{mV} \mathrm{s}^{-1}$ ) shown in Figure 8 were acquired by scanning the applied potential from the rest value $\left(E_{\text {eq }}\right)$ to $-0.5 \mathrm{~V}$ under intermittent illumination provided by a solar simulator $(100$ $\mathrm{mW} \mathrm{cm} \mathrm{cm}^{-2}$ ). Prior thermal annealing at $150{ }^{\circ} \mathrm{C}$ did not cause any visible change in the XRD, XPS, and DRS analyses compared to the as-synthesized sample, while adhesion to the FTO substrate was promoted. Therefore, this sample could be represented as $\mathrm{Cu}_{2} \mathrm{WO}_{4}$. Since a cathodic photocurrent was observed which increased at more negative (reverse bias) potentials, arc-synthesized $\mathrm{Cu}_{2} \mathrm{WO}_{4}$ was diagnosed as a p-type semiconductor.

On band-gap photoexcitation, the photogenerated holes migrate to the back contact, while the electrons at the 

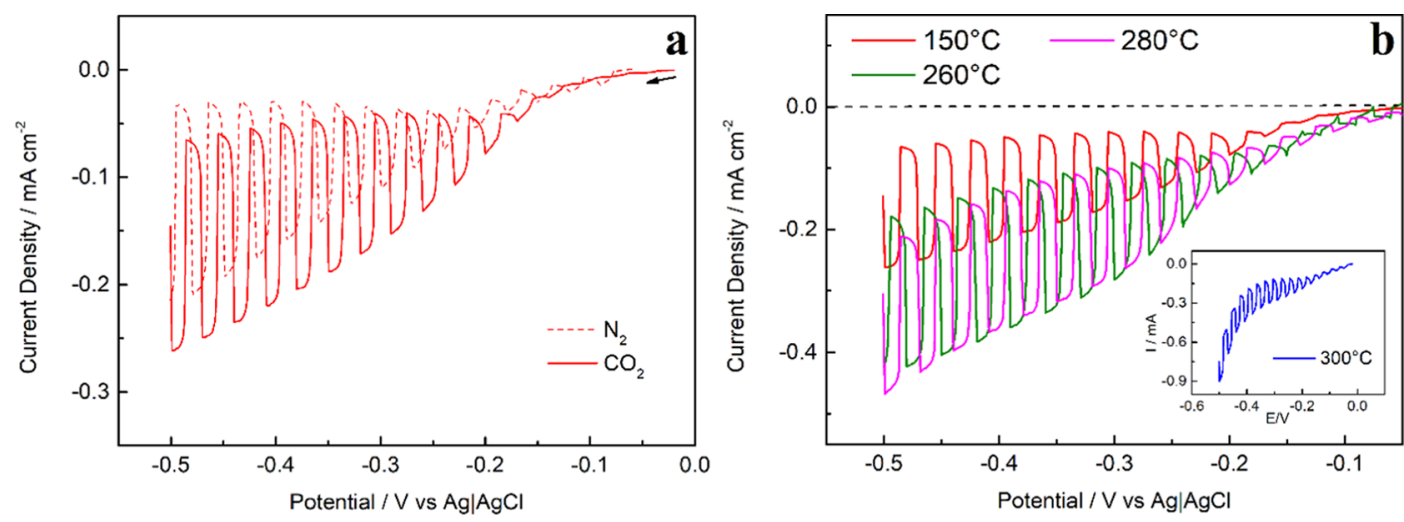

Figure 8. (a) Photovoltammograms obtained under intermittent light incidence in aqueous $0.5 \mathrm{M} \mathrm{NaHCO}_{3}$ solution from $\mathrm{Cu}_{2} \mathrm{WO}_{4}$ electrodes preannealed at $150{ }^{\circ} \mathrm{C}$, in electrolyte saturated with $\mathrm{N}_{2}$ and $\mathrm{CO}_{2}$. (b) Photovoltammograms for FTO- $\mathrm{Cu}_{2} \mathrm{WO}_{4}$ electrodes preannealed at 150,260 , and $280{ }^{\circ} \mathrm{C}$ (red, green, and magenta lines, respectively) in solutions saturated with $\mathrm{CO}_{2}$. The inset shows data for the sample preannealed at 300 ${ }^{\circ} \mathrm{C}$.

electrode surface react with dissolved $\mathrm{CO}_{2}$ in the aqueous solution interface. It is worth noting here that the photocurrent was significantly higher in the presence of $\mathrm{CO}_{2}$, compared to the $\mathrm{N}_{2}$-bubbled electrolyte case (Figure $8 \mathrm{a}$ ). We assume that the photogenerated species reduce dissolved $\mathrm{CO}_{2}$ species in solution via redox processes that are beyond the scope of discussion in the present study.

As the sample was further oxidized (e.g., after $260{ }^{\circ} \mathrm{C}$ thermal preannealing), the photocurrent was slightly enhanced, while the dark current also increased to a significant extent (Figure $8 \mathrm{~b}$ ). The behavior now reflects that of the mixedvalence tungstate. At some point, the amount of $\mathrm{Cu}^{2+}$ sites became detrimental to the photoactivity, and electroactivity in the dark became dominant $\left(300{ }^{\circ} \mathrm{C}\right.$ annealing, Figure $8 \mathrm{~b}$, inset), although some cathodic photocurrent is still observed, which agrees with $\mathrm{CuWO}_{4}$ being formed along with p-type $\mathrm{CuO}$ via the oxidation pathway described in eq 1 .

As copper(II) tungstate is known to be an n-type semiconductor, metal-like behavior is expected at forward bias and this is indeed reflected in the data in Figure 8 (inset). This switch in both structures (cf. Figure 6) and electronic properties accounts for the trends with annealing temperature, seen in Figure 8. Figure S12 shows the correlation between $\mathrm{Cu}^{2+}$ content extracted from XPS data and the dark current at the selected potential of $-0.45 \mathrm{~V}$ vs $\mathrm{Ag} \mid \mathrm{AgCl}$. Interestingly, different ratios of mixed valence in a broad range did not alter the dark current values noticeably.

Finally, as shown in Figure S13, flat band potentials $\left(V_{\mathrm{fb}}\right)$ of $\mathrm{Cu}_{2} \mathrm{WO}_{4}$ were experimentally obtained by the Butler-Gärtner methodology $^{61}$ (see the Supporting Information). Interestingly, the values for $V_{\mathrm{fb}}$ of $\mathrm{Cu}_{2} \mathrm{WO}_{4}$ and the mixed-valence copper tungstates were the same. The $V_{\mathrm{fb}}$ and $E_{\mathrm{bg}}$ values can be combined to obtain band edge positions (VB and $\mathrm{CB}$ ) for a given oxide. Figure 9 shows the band positions of $\mathrm{Cu}_{2} \mathrm{WO}_{4}$ thus obtained in this work, compared to literature values for $\mathrm{Cu}_{2} \mathrm{O}$ and other p-type, $\mathrm{Cu}^{+}$complex oxides. ${ }^{54,56,62,63}$ In constructing this diagram using the data from Figure S13 and literature sources, a Nernstian correction (of $-0.059 \mathrm{~V} / \mathrm{pH}$ ) was also made when needed, to obtain values on the reversible hydrogen electrode (RHE) scale.

The literature data ${ }^{12}$ for $\mathrm{CuWO}_{4}$ band edge positions indicate a much more positive conduction band minimum. However, $\mathrm{Cu}_{2} \mathrm{WO}_{4}$ has a $3 \mathrm{~d}^{10}$ electronic configuration; therefore, the $\mathrm{CB}$ is mainly composed of $\mathrm{W} 5 \mathrm{~d}^{0}$ orbitals. On

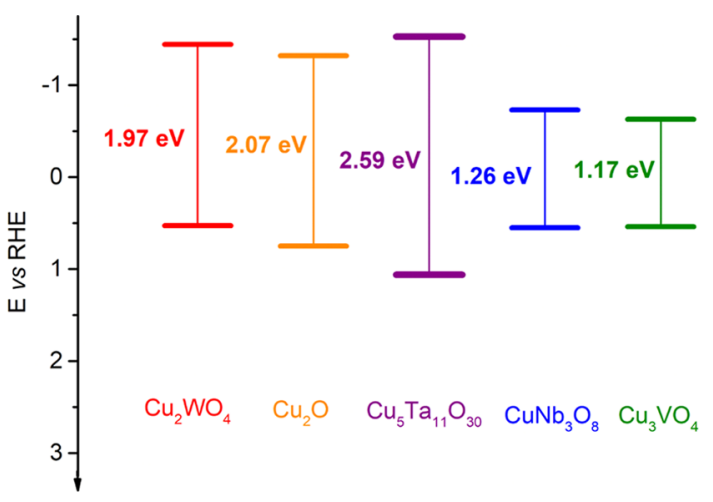

Figure 9. Band positions of arc-melted $\mathrm{Cu}_{2} \mathrm{WO}_{4}$ determined by combining optical band gap measurements and flat band potentials $\left(V_{\mathrm{fb}}\right)$ extracted from Butler-Gärtner plots.

the other hand, $\mathrm{CuWO}_{4}$ has a $3 \mathrm{~d}^{9}$ configuration leading to a different orbital composition for the corresponding CB. As can be seen in Figure 5, our calculations show that $\mathrm{CuWO}_{4}$ has a mid-gap state mainly composed of $\mathrm{Cu}-\mathrm{d}$ orbitals. Experimental determination of $\mathrm{CuWO}_{4} \mathrm{CB}$ energy ${ }^{12}$ did not initially consider this feature. In fact, the same authors later discussed this mid-gap state in a more detailed EIS study. ${ }^{64}$ Insights on the influence of mid-gap states when determining CBM values of $\mathrm{CuWO}_{4}$ are provided in more recent work from the same authors. ${ }^{65}$

In terms of structural aspects, the copper coordination environment has an important influence on the energy levels of metal oxide semiconductors. For instance, a higher coordination of copper atoms tends to provide narrow band gaps for some family of copper complex oxides, ${ }^{5}$ although more commonly by shifting the valence band.

The very negative $\mathrm{CB}$ edge positions for the p-type copper oxides (Figure 9) underline why they are of much current interest. A high driving force (i.e., overpotential) for photoredox reactions involving negative redox potentials, is intrinsic to the electronic structure of these compounds. This feature could be exploited for many practical device applications including energy conversion and sensors.

Stability issues hamper the widespread use of copper oxides, especially for photoelectrochemical applications. For example, the parent oxide $\mathrm{Cu}_{2} \mathrm{O}$ is known to undergo photoreduction (to metallic copper) in aqueous solutions, as the potential for 
this redox process lies inside the energy band gap. ${ }^{66-68}$ Therefore, the photoelectrochemical stability of $\mathrm{Cu}_{2} \mathrm{WO}_{4}$ was compared with that of $\mathrm{Cu}_{2} \mathrm{O}$; the data are contained in Figure 10 .
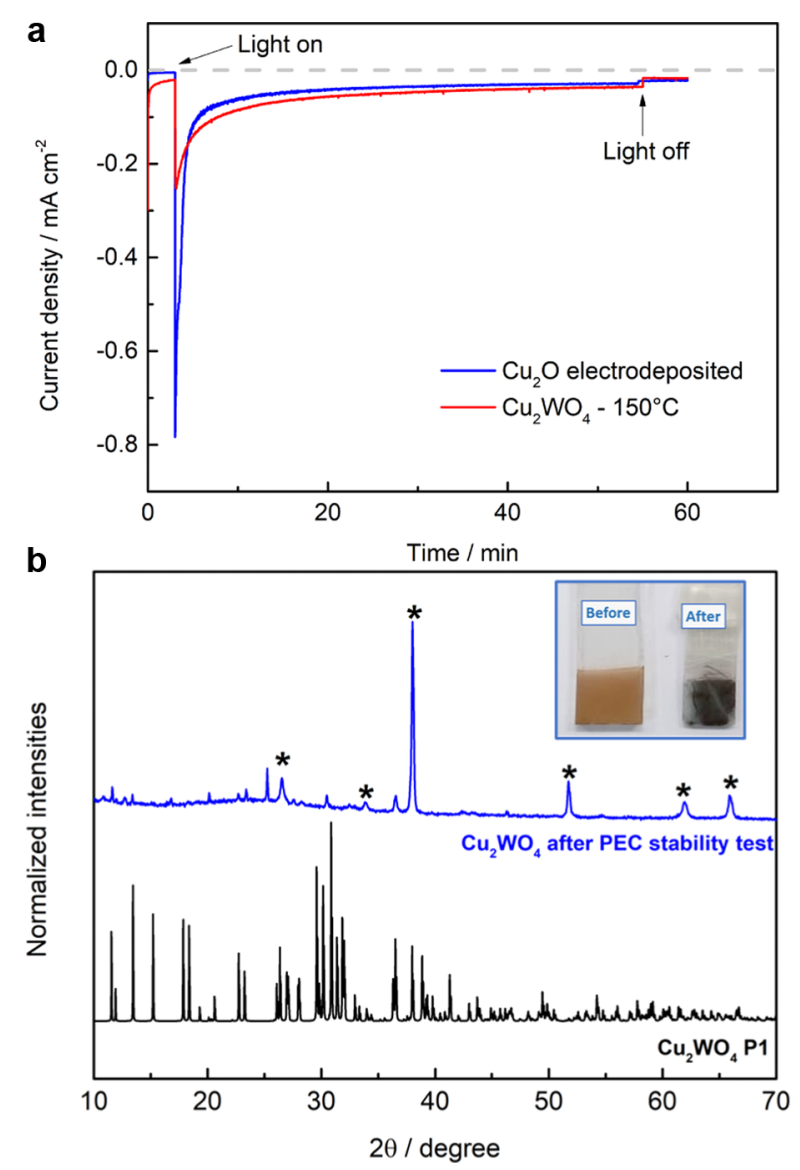

Figure 10. (a) Chronoamperometric PEC stability test performed at $-0.3 \mathrm{~V}$ vs $\mathrm{Ag} \mid \mathrm{AgCl}$ under 1 sun illumination for $60 \mathrm{~min}$. (b) XRD analysis of $\mathrm{Cu}_{2} \mathrm{WO}_{4}$ cathode after stability test.

Electrodes of $\mathrm{Cu}_{2} \mathrm{WO}_{4}$ were preannealed at $150{ }^{\circ} \mathrm{C}$ and electrodeposited $\mathrm{Cu}_{2} \mathrm{O}$ were polarized at $-0.3 \mathrm{~V}$ and kept under illumination for $50 \mathrm{~min}$. As expected, both $\mathrm{Cu}_{2} \mathrm{O}$ and $\mathrm{Cu}_{2} \mathrm{WO}_{4}$ underwent photocorrosion as demonstrated by the gradual photocurrent decay with time (Figure 10a). Nonetheless, the decay was more pronounced for $\mathrm{Cu}_{2} \mathrm{O}$, indicating enhanced stability for the $\mathrm{Cu}_{2} \mathrm{WO}_{4}$ photocathode, although severe photocorrosion did occur. Figure $10 \mathrm{~b}$ shows the XRD analysis of the $\mathrm{Cu}_{2} \mathrm{WO}_{4}$ photoelectrode after the stability test. The main diffraction peaks were identified as the FTO substrate, indicating detachment of copper tungstate from the conductive support. Minor diffraction peaks could be related to $\mathrm{CuWO}_{4}$, although not unambiguously. Formation of $\mathrm{CuO}$ or $\mathrm{Cu}$ was ruled out, which suggests photocorrosion leading to $\mathrm{CuWO}_{4}$ accompanied by copper leaching into the solution. The mechanistic aspects of photocorrosion of $\mathrm{Cu}_{2} \mathrm{WO}_{4}$, as well as different strategies for electrode protection against photocorrosion, constitute topics beyond the scope of this study, and will be the subject of follow-up work.

\section{CONCLUSIONS}

In conclusion, a hitherto little-studied $\mathrm{Cu}(\mathrm{I})$ tungstate $\left(\mathrm{Cu}_{2} \mathrm{WO}_{4}\right)$ was studied by a combined theoretical/exper- imental approach. The long-standing debate on the crystal structure was resolved, and $\mathrm{Cu}_{2} \mathrm{WO}_{4}$ was theoretically shown to belong to the $P 1$ space group. $\mathrm{Cu}_{2} \mathrm{WO}_{4}$ was obtained by a simple, time-efficient synthesis using an arc furnace. This material possessed broad-band light absorption in the entire $\mathrm{UV}-$ vis spectrum. Photoelectrodes of $\mathrm{Cu}_{2} \mathrm{WO}_{4}$ showed cathodic photocurrent in the presence of $\mathrm{CO}_{2}$ in aqueous solution, when polarized at more negative potentials than the rest potential; this was diagnostic of p-type semiconductor behavior. Prior thermal annealing of $\mathrm{Cu}_{2} \mathrm{WO}_{4}$ was demonstrated to induce mixed-valent behavior up to $260{ }^{\circ} \mathrm{C}$, with higher temperatures inducing oxidation to $\mathrm{CuWO}_{4}$ along with expulsion of $\mathrm{CuO}$ from the compound structure. Finally, the present study has served to address a significant literature void that existed for an interesting ternary copper oxide based on earth-abundant elements and obtained by simple processing methods, two important aspects for reaching economically feasible solar fuels technologies. ${ }^{69}$

\section{ASSOCIATED CONTENT}

\section{Supporting Information}

The Supporting Information is available free of charge at https://pubs.acs.org/doi/10.1021/acsami.1c03928.

Calculated infrared spectra and atomic positions of relaxed geometries for structures based on the two space groups; partial charge densities at the VBM and CBM; thermal analysis data; effect of preannealing on XRD and DRS data; high-resolution XPS data in the O 1s and W $4 \mathrm{f}$ domains as a function of preannealing temperature; SEM image of $\mathrm{Cu}_{2} \mathrm{WO}_{4}$ photoelectrode; Butler-Gartner analyses; Bader charge analyses for copper(I) tungstate and copper(II) tungstate; and images of arc synthesis setup (PDF)

\section{AUTHOR INFORMATION}

\section{Corresponding Authors}

Nora H. de Leeuw - Department of Earth Sciences, Utrecht University, 3548CB Utrecht, The Netherlands; School of Chemistry, University of Leeds, Leeds LS2 9JT, United Kingdom; Email: n.h.deleeuw@uu.nl,n.h.deleeuw@ leeds.ac.uk

Claudia Longo - Institute of Chemistry, University of Campinas-UNICAMP, 13083-970 Campinas, Brazil; Center for Innovation on New Energies, University of Campinas, 13083-841 Campinas, Brazil; 으잉.org/ 0000-0001-8955-148X; Email: clalongo@unicamp.br

\section{Authors}

Miguel Tayar Galante - Institute of Chemistry, University of Campinas-UNICAMP, 13083-970 Campinas, Brazil; Center for Innovation on New Energies, University of Campinas, 13083-841 Campinas, Brazil; 이잉.org/ 0000-0003-1697-0039

Aleksandar Živković - Department of Earth Sciences, Utrecht University, 3548CB Utrecht, The Netherlands; 10 orcid.org/ 0000-0003-1347-6203

Jéssica Costa Alvim - Institute of Chemistry, University of Campinas-UNICAMP, 13083-970 Campinas, Brazil; Center for Innovation on New Energies, University of Campinas, 13083-841 Campinas, Brazil 
Cinthia Cristina Calchi Kleiner - Faculty of Mechanical Engineering, University of Campinas-UNICAMP, 13083970 Campinas, Brazil

Márcio Sangali - Faculty of Mechanical Engineering, University of Campinas-UNICAMP, 13083-970 Campinas, Brazil

S. F. Rebecca Taylor - Department of Chemical Engineering and Analytical Science, University of Manchester, Manchester M13 9PL, United Kingdom; 이이.org/0000-0002-61752631

Adam J. Greer - Department of Chemical Engineering and Analytical Science, University of Manchester, Manchester M13 9PL, United Kingdom; (1) orcid.org/0000-0003-16395433

Christopher Hardacre - Department of Chemical Engineering and Analytical Science, University of Manchester, Manchester M13 9PL, United Kingdom; iorcid.org/0000-0001-72566765

Krishnan Rajeshwar - Department of Chemistry and Biochemistry, The University of Texas at Arlington, Arlington, Texas 76019, United States; ㅇo이.org/00000003-4917-7790

Rubens Caram - Faculty of Mechanical Engineering, University of Campinas-UNICAMP, 13083-970 Campinas, Brazil

Rodnei Bertazzoli - Faculty of Mechanical Engineering, University of Campinas-UNICAMP, 13083-970 Campinas, Brazil

Robin T. Macaluso - Department of Chemistry and Biochemistry, The University of Texas at Arlington, Arlington, Texas 76019, United States; 이이.org/00000002-0021-0775

Complete contact information is available at:

https://pubs.acs.org/10.1021/acsami.1c03928

\section{Author Contributions}

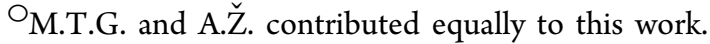

\section{Notes}

The authors declare no competing financial interest.

\section{ACKNOWLEDGMENTS}

The authors gratefully acknowledge Dr. Flavia Cassiola and her team at Shell Technologies Center Houston for the valuable support in SEM analyses. M.T.G., J.C.A., and C.L. acknowledge support from National Council for Scientific and Technological Development (CNPq), Unicamp Fund for Support to Teaching, Research and Outreach Activities (FAEPEX Unicamp/Cardiff Mobility program), CAPESPrInt Program (Process 88881.310535/2018-01), FAPESP (the São Paulo Research Foundation, Processes 2017/119865) and Shell and the strategic importance of the support given by ANP (Brazil's National Oil, Natural Gas and Biofuels Agency) through the $R \& D$ levy regulation. R.B. also acknowledges the support from FAPESP, Process 2019/ 11353-8. C.H., R.T., A.G., and N.H.d.L. acknowledge funding from the EPSRC under grant no. EP/N009533/1, MultiDisciplinary Approach to Generating Low Carbon Fuels, carried out in collaboration with the University of Manchester, Queen's University Belfast, Cardiff University, and University College London. Open access data can be found via the University of Manchester research portal. A.Z. and N.H.d.L. acknowledge the NWO ECHO grant (712.018.005) for funding. The computational work was carried out on the Dutch national e-infrastructure with the support of the SURF Cooperative. The authors thank the four anonymous reviewers for constructive criticisms of an earlier manuscript version.

\section{REFERENCES}

(1) George, J. M.; Antony, A.; Mathew, B. Metal Oxide Nanoparticles in Electrochemical Sensing and Biosensing: A Review. Microchim. Acta 2018, 185, No. 358.

(2) Al-Jawhari, H. A. A Review of Recent Advances in Transparent p-Type $\mathrm{Cu}_{2} \mathrm{O}$-Based Thin Film Transistors. Mater. Sci. Semicond. Process. 2015, 40, 241-252.

(3) Rajeshwar, K.; Hossain, M. K.; Macaluso, R. T.; Janáky, C.; Varga, A.; Kulesza, P. J. Review-Copper Oxide-Based Ternary and Quaternary Oxides: Where Solid-State Chemistry Meets Photoelectrochemistry. J. Electrochem. Soc. 2018, 165, H3192-H3206.

(4) Sivula, K.; van de Krol, R. Semiconducting Materials for Photoelectrochemical Energy Conversion. Nat. Rev. Mater. 2016, 1, No. 15010.

(5) Sullivan, I.; Zoellner, B.; Maggard, P. A. Copper(I)-Based p -Type Oxides for Photoelectrochemical and Photovoltaic Solar Energy Conversion. Chem. Mater. 2016, 28, 5999-6016.

(6) Cerqueira, T. F. T.; Lin, S.; Amsler, M.; Goedecker, S.; Botti, S.; Marques, M. aL. Identification of Novel $\mathrm{Cu}, \mathrm{Ag}$, and $\mathrm{Au}$ Ternary Oxides from Global Structural Prediction. Chem. Mater. 2015, 27, $4562-4573$.

(7) Joshi, U. A.; Maggard, P. A. $\mathrm{CuNb}_{3} \mathrm{O}_{8}$ : A p-Type Semiconducting Metal Oxide Photoelectrode. J. Phys. Chem. Lett. 2012, 3, $1577-1581$

(8) Cardenas-Morcoso, D.; Peiro-Franch, A.; Herraiz-Cardona, I.; Gimenez, S. Chromium Doped Copper Vanadate Photoanodes for Water Splitting. Catal. Today 2017, 290, 65-72.

(9) Sharma, G.; Zhao, Z.; Sarker, P.; Nail, B. A.; Wang, J.; Huda, M.; Osterloh, F. Electronic Structure, Photovoltage, and Photocatalytic Hydrogen Evolution with p-CuBi ${ }_{2} \mathrm{O}_{4}$ Nanocrystals. J. Mater. Chem. A 2016, 4, 2936-2942.

(10) Kamimura, S.; Murakami, N.; Tsubota, T.; Ohno, T. Fabrication and Characterization of a p-Type $\mathrm{Cu}_{3} \mathrm{Nb}_{2} \mathrm{O}_{8}$ Photocathode toward Photoelectrochemical Reduction of Carbon Dioxide. Appl. Catal., B 2015, 174-175, 471-476.

(11) Wang, Y.; Miska, P.; Pilloud, D.; Horwat, D.; Pierson, J. F. Transmittance Enhancement and Optical Band Gap Widening of $\mathrm{Cu}_{2} \mathrm{O}$ Thin Films after Air Annealing. J. Appl. Phys. 2017, 115, No. 073505.

(12) Yourey, J. E.; Bartlett, B. M. Electrochemical Deposition and Photoelectrochemistry of $\mathrm{CuWO}_{4}$, a Promising Photoanode for Water Oxidation. J. Mater. Chem. 2011, 21, 7651-7660.

(13) Wu, Z.; Zhao, Z.; Cheung, G.; Doughty, R. M.; Ballestasbarrientos, A. R.; Hirmez, B.; Han, R.; Maschmeyer, T.; Osterloh, F. E. Role of Surface States in Photocatalytic Oxygen Evolution with $\mathrm{CuWO}_{4}$ Particles. J. Electrochem. Soc. 2019, 166, H3014-H3019.

(14) Ma, Z.; Linnenberg, O.; Rokicinska, A.; Kustrowki, P.; Slabon, A. Augmenting the Photocurrent of $\mathrm{CuWO}_{4}$ Photoanodes by Heat Treatment in the Nitrogen Atmosphere. J. Phys. Chem. C 2018, 122, 19281-19288.

(15) Lin, Z.; Li, W.; Yang, G. Hydrogen-Interstitial $\mathrm{CuWO}_{4}$ nanomesh: A Single-Component Full Spectrum-Active Photocatalyst for Hydrogen Evolution. Appl. Catal., B 2018, 227, 35-43.

(16) Marinder, B.-O.; Wang, P.-L.; Werner, P.-E.; Westdahl, M.; Andresen, A. F.; Louër, D. Powder Diffraction Studies of $\mathrm{Cu}_{2} \mathrm{WO}_{4}$. Acta Chem. Scand. 1987, 41a, 152-157.

(17) Mumm, H.-C.; Müller-Buschbaum, H. Zur Kristallstruktur von $\mathrm{Cu}_{2} \mathrm{WO}_{4}$. J. Less-Common Met. 1988, 142, 85-90.

(18) Zunger, A. Inverse Design in Search of Materials with Target Functionalities. Nat. Rev. Chem. 2018, 2, No. 0121.

(19) Kresse, G.; Joubert, D. From Ultrasoft Pseudopotentials to the Projector Augmented-Wave Method. Phys. Rev. B 1999, 59, 17581775. 
(20) Kresse, G.; Furthmüller, J. Efficient Iterative Schemes for Ab Initio Total-Energy Calculations Using a Plane-Wave Basis Set. Phys. Rev. B 1996, 54, 11169-11186.

(21) Kresse, G.; Furthmüller, J. Efficiency of Ab-Initio Total Energy Calculations for Metals and Semiconductors Using a Plane-Wave Basis Set. Comput. Mater. Sci. 1996, 6, 15-50.

(22) Perdew, J. P.; Burke, K.; Ernzerhof, M. Generalized Gradient Approximation Made Simple. Phys. Rev. Lett. 1996, 77, 3865-3868.

(23) Heyd, J.; Scuseria, G. E.; Ernzerhof, M. Hybrid Functionals Based on a Screened Coulomb Potential. J. Chem. Phys. 2003, 118, $8207-8215$.

(24) Heyd, J.; Scuseria, G. E. Efficient Hybrid Density Functional Calculations in Solids: Assessment of the Heyd-Scuseria-Ernzerhof Screened Coulomb Hybrid Functional. J. Chem. Phys. 2004, 121, $1187-1192$.

(25) Heyd, J.; Scuseria, G. E.; Ernzerhof, M. Erratum: "Hybrid Functionals Based on a Screened Coulomb Potential" [J. Chem. Phys. 118, 8207 (2003)]. J. Chem. Phys. 2006, 124, No. 219906.

(26) Gajdoš, M.; Hummer, K.; Kresse, G.; Furthmüller, J.; Bechstedt, F. Linear Optical Properties in the Projector-Augmented Wave Methodology. Phys. Rev. B 2006, 73, No. 045112.

(27) Grimme, S.; Antony, J.; Ehrlich, S.; Krieg, H. A Consistent and Accurate Ab Initio Parametrization of Density Functional Dispersion Correction (DFT-D) for the 94 Elements H-Pu. J. Chem. Phys. 2010, 132, No. 154104.

(28) Monkhorst, H. J.; Pack, J. D. Special Points for Brillouin-Zone Integrations. Phys. Rev. B 1976, 13, 5188-5192.

(29) Yu, M.; Trinkle, D. R. Accurate and Efficient Algorithm for Bader Charge Integration. J. Chem. Phys. 2011, 134, No. 064111.

(30) Tang, W.; Sanville, E.; Henkelman, G. A Grid-Based Bader Analysis Algorithm without Lattice Bias. J. Phys.: Condens. Matter 2009, 21, No. 084204.

(31) Sanville, E.; Kenny, S. D.; Smith, R.; Henkelman, G. Improved Grid-Based Algorithm for Bader Charge Allocation. J. Comput. Chem. 2007, 28, 899-908.

(32) Momma, K.; Izumi, F. VESTA 3 for Three-Dimensional Visualization of Crystal, Volumetric and Morphology Data. J. Appl. Crystallogr. 2011, 44, 1272-1276.

(33) Ganose, A. M.; J Jackson, A. J.; O Scanlon, D. O. Sumo: Command-Line Tools for Plotting and Analysis of Periodic Ab Initio Calculations. J. Open Source Software 2018, 3, 717.

(34) Wang, V.; Xu, N.; Liu, J. C.; Tang, G.; Geng, W.-T.. VASPKIT: A Pre- and Post-Processing Program for VASP Code, 2019; pp 1-16.

(35) Dovesi, R.; Saunders, V. R.; Roetti, C.; Orlando, R.; ZicovichWilson, C. M.; Pascale, F.; Civalleri, B.; Doll, K.; Harrison, N. M.; Bush, I. J.; D’Arco, P.; Llunell, M.; Causà, M.; Noël, Y.; Maschio, L.; Erba, A.; Rerat, M.; Casassa, S. CRYSTAL17 User's Manual; University of Torino: Torino, 2017.

(36) Dovesi, R.; Erba, A.; Orlando, R.; Zicovich-Wilson, C. M.; Civalleri, B.; Maschio, L.; Rérat, M.; Casassa, S.; Baima, J.; Salustro, S.; Kirtman, B. Quantum-Mechanical Condensed Matter Simulations with CRYSTAL. WIREs Comput. Mol. Sci. 2018, 8, No. e1360.

(37) Becke, A. D. A New Mixing of Hartree-Fock and Local Density-functional Theories. J. Chem. Phys. 1993, 98, No. 1372.

(38) Lee, C.; Yang, W.; Parr, R. G. Development of the ColleSalvetti Correlation-Energy Formula into a Functional of the Electron Density. Phys. Rev. B 1988, 37, 785-789.

(39) Linnera, J.; Karttunen, A. J. Ab Initio Study of the Lattice Thermal Conductivity of $\mathrm{Cu}_{2} \mathrm{O}$ Using the Generalized Gradient Approximation and Hybrid Density Functional Methods. Phys. Rev. B 2017, 96, No. 014304.

(40) Linnera, J.; Sansone, G.; Maschio, L.; Karttunen, A. J. Thermoelectric Properties of P-Type $\mathrm{Cu}_{2} \mathrm{O}, \mathrm{CuO}$, and $\mathrm{NiO}$ from Hybrid Density Functional Theory. J. Phys. Chem. C 2018, 122, 15180-15189.

(41) Hay, P. J.; Wadt, W. R. Ab Initio Effective Core Potentials for Molecular Calculations. Potentials for the Transition Metal Atoms Sc to Hg. J. Chem. Phys. 1985, 82, 270-283.
(42) Wang, F.; Di Valentin, C.; Pacchioni, G. Electronic and Structural Properties of $\mathrm{WO}_{3}$ : A Systematic Hybrid DFT Study. J. Phys. Chem. C 2011, 115, 8345-8353.

(43) De La Pierre, M.; Carteret, C.; Maschio, L.; André, E.; Orlando, R.; Dovesi, R. The Raman Spectrum of $\mathrm{CaCO}_{3}$ Polymorphs Calcite and Aragonite: A Combined Experimental and Computational Study. J. Chem. Phys. 2014, 140, No. 164509.

(44) Prencipe, M.; Pascale, F.; Zicovich-Wilson, C. M.; Saunders, V. R.; Orlando, R.; Dovesi, R. The Vibrational Spectrum of Calcite $\left(\mathrm{CaCO}_{3}\right)$ : An $\mathrm{Ab}$ Initio Quantum-Mechanical Calculation. Phys. Chem. Miner. 2004, 31, 559-564.

(45) Maschio, L.; Kirtman, B.; Orlando, R.; Rèrat, M. Ab Initio Analytical Infrared Intensities for Periodic Systems through a Coupled Perturbed Hartree-Fock/Kohn-Sham Method. J. Chem. Phys. 2012, 137, No. 204113

(46) Maschio, L.; Kirtman, B.; Rérat, M.; Orlando, R.; Dovesi, R. Ab Initio Analytical Raman Intensities for Periodic Systems through a Coupled Perturbed Hartree-Fock/Kohn-Sham Method in an Atomic Orbital Basis. II. Validation and Comparison with Experiments. J. Chem. Phys. 2013, 139, No. 164102.

(47) Maschio, L.; Kirtman, B.; Rérat, M.; Orlando, R.; Dovesi, R. Ab Initio Analytical Raman Intensities for Periodic Systems through a Coupled Perturbed Hartree-Fock/Kohn-Sham Method in an Atomic Orbital Basis. I. Theory. J. Chem. Phys. 2013, 139, No. 164101.

(48) Dovesi, R.; Kirtman, B.; Maschio, L.; Maul, J.; Pascale, F.; Rérat, M. Calculation of the Infrared Intensity of Crystalline Systems. A Comparison of Three Strategies Based on Berry Phase, Wannier Function, and Coupled-Perturbed Kohn-Sham Methods. J. Phys. Chem. C 2019, 123, 8336-8346.

(49) Stokes, H. T.; Hatch, D. M. FINDSYM: Program for Identifying the Space-Group Symmetry of a Crystal. J. Appl. Crystallogr. 2005, 38, 237-238.

(50) Kubicki, J. D.; Watts, H. D. Quantum Mechanical Modeling of the Vibrational Spectra of Minerals with a Focus on Clays. Minerals 2019, 9, No. 141.

(51) Alver, Ö. FT-IR, Raman and DFT Studies on the Vibrational Spectra of 2,2-Bis(Aminoethoxy)Propane. Bull. Chem. Soc. Ethiop. 2016, 30, 147-151.

(52) Khomskii, D. I. Transition Metal Compounds; Cambridge University Press: Cambridge, 2014.

(53) Tian, C. M.; Jiang, M.; Tang, D.; Qiao, L.; Xiao, H. Y.; Oropeza, F. E.; Hofmann, J. P.; Hensen, E. J. M.; Tadich, A.; Li, W.; Qi, D. C.; Zhang, K. H. L. Elucidating the Electronic Structure of $\mathrm{CuWO}_{4}$ Thin Films for Enhanced Photoelectrochemical Water Splitting. J. Mater. Chem. A 2019, 7, 11895-11907.

(54) King, N.; Sahoo, P. P.; Fuoco, L.; Stuart, S.; Dougherty, D.; Liu, Y.; Maggard, P. A. Copper Deficiency in the p-Type Semiconductor $\mathrm{Cu}_{1-} \mathrm{Nb}_{3} \mathrm{O}_{8}$. Chem. Mater. 2014, 26, 2095-2104.

(55) Zoellner, B.; Stuart, S.; Chung, C.; Dougherty, D. B.; Jones, J. L.; Maggard, P. A. $\mathrm{CuNb}_{1-\mathrm{x}} \mathrm{Ta}_{\mathrm{x}} \mathrm{O}_{3}(\mathrm{x} \leq 0.25)$ Solid Solutions: Impact of $\mathrm{Ta}(\mathrm{V})$ Substitution and $\mathrm{Cu}(\mathrm{I})$ Deficiency on Their Structure, Photocatalytic, and Photoelectrochemical Properties. J. Mater. Chem. A 2016, 4, 3115-3126.

(56) Sahoo, P. P.; Zoellner, B.; Maggard, P. A. Optical, Electronic, and Photoelectrochemical Properties of the p-Type $\mathrm{Cu}_{3-\mathrm{x}} \mathrm{VO}_{4}$ Semiconductor. J. Mater. Chem. A 2015, 3, 4501-4509.

(57) Kunturu, P. P.; Huskens, J. Efficient Solar Water Splitting Photocathodes Comprising a Copper Oxide Heterostructure Protected by a Thin Carbon Layer. ACS Appl. Energy Mater. 2019, 2, 7850-7860.

(58) Fleisch, T. H.; Mains, G. J. Reduction of Copper Oxides by UV Radiation and Atomic Hydrogen Studied by XPS. Appl. Surf. Sci. 1982, 10, 51-62.

(59) Köhler, B. U.; Jansen, M. Darstellung Und Strukturdaten von "Delafossiten" $\mathrm{CuMO}_{2}(\mathrm{M}=\mathrm{Al}, \mathrm{Ga}, \mathrm{Sc}, \mathrm{Y})$. Z. Anorg. Allg. Chem. 1986, 543, 73-80.

(60) Teske, C. L.; Müller-Buschbaum, H. Über ErdalkalimetallOxocuprate. IV. Zur Kenntnis von $\mathrm{SrCu}_{2} \mathrm{O}_{2}$. Z. Anorg. Allg. Chem. 1970, 379, 113-121. 
(61) Butler, M. A. Photoelectrolysis and Physical Properties of the Semiconducting Electrode $\mathrm{WO}_{3}$. J. Appl. Phys. 1977, 48, 1914-1920.

(62) Paracchino, A.; Brauer, J. C.; Moser, J.-E.; Thimsen, E.; Graetzel, M. Synthesis and Characterization of High-Photoactivity Electrodeposited $\mathrm{Cu}_{2} \mathrm{O}$ Solar Absorber by Photoelectrochemistry and Ultrafast Spectroscopy. J. Phys. Chem. C 2012, 116, 7341-7350.

(63) Sullivan, I.; Sahoo, P. P.; Fuoco, L.; Hewitt, A. S.; Stuart, S.; Dougherty, D.; Maggard, P. A. Cu-Deficiency in the p -Type Semiconductor $\mathrm{Cu}_{5-\mathrm{x}} \mathrm{Ta}_{11} \mathrm{O}_{30}$ : Impact on Its Crystalline Structure, Surfaces, and Photoelectrochemical Properties. Chem. Mater. 2014, 26, 6711-6721.

(64) Pyper, K. J.; Yourey, J. E.; Bartlett, B. M. Reactivity of $\mathrm{CuWO}_{4}$ in Photoelectrochemical Water Oxidation Is Dictated by a Midgap Electronic State. J. Phys. Chem. C 2013, 117, 24726-24732.

(65) Lhermitte, C. R.; Bartlett, B. M. Advancing the Chemistry of $\mathrm{CuWO}_{4}$ for Photoelectrochemical Water Oxidation. Acc. Chem. Res. 2016, 49, 1121-1129.

(66) Gerischer, H. On the Stability of Semiconductor Electrodes against Photodecomposition. J. Electroanal. Chem. Interfacial Electrochem. 1977, 82, 133-143.

(67) Rajeshwar, K.; de Tacconi, N. R.; Ghadimkhani, G.; Chanmanee, W.; Janáky, C. Tailoring Copper Oxide Semiconductor Nanorod Arrays for Photoelectrochemical Reduction of Carbon Dioxide to Methanol. ChemPhysChem 2013, 14, 2251-2259.

(68) Ghadimkhani, G.; de Tacconi, N. R.; Chanmanee, W.; Janaky, C.; Rajeshwar, K. Efficient Solar Photoelectrosynthesis of Methanol from Carbon Dioxide Using Hybrid $\mathrm{CuO}-\mathrm{Cu}_{2} \mathrm{O}$ Semiconductor Nanorod Arrays. Chem. Commun. 2013, 49, 1297-1299.

(69) Sivula, K. Toward Economically Feasible Direct Solar-to-Fuel Energy Conversion. J. Phys. Chem. Lett. 2015, 6, 975-976. 